\title{
Paediatricians and the new National Health Service
}

\author{
Cyril Chantler
}

There is anxiety among paediatricians about the new NHS that is to be introduced in April 1991. Some concerns are shared by others from different disciplines who work in the NHS, some are particular to paediatricians. The purpose of this paper is to discuss the reasons for the changes and to suggest appropriate responses for paediatricians.

\section{Background}

The crisis about the funding of the NHS developed slowly over the decade after the introduction of strict control over public expenditure in 1976 as part of the terms of a loan from the International Monetary Fund to the British government. $^{2}$ Initially, inflation cause by pay awards over the cash limit was corrected in the subsequent year, but since 1982 financial management has included cumulative underfunding of pay awards so that service growth has relied on efficiency savings. It is tempting but unrealistic to wish to return to the days when a doctor could obtain the resources he needed to treat his patients simply by stating his case to his colleagues and the health authorities. It is also tempting to say that all that is required is to increase the proportion of the gross domestic product that is spent on health care in the United Kindom. This presumes that the amount spent in the United Kingdom is appre-

United Medical and Dental Schools of Guy's and St Thomas's Hospital, London

Correspondence to: Professor Cyril Chantler, Dean's Office, Guy's Hospital, St Thomas's Street, London SE1 9RT.

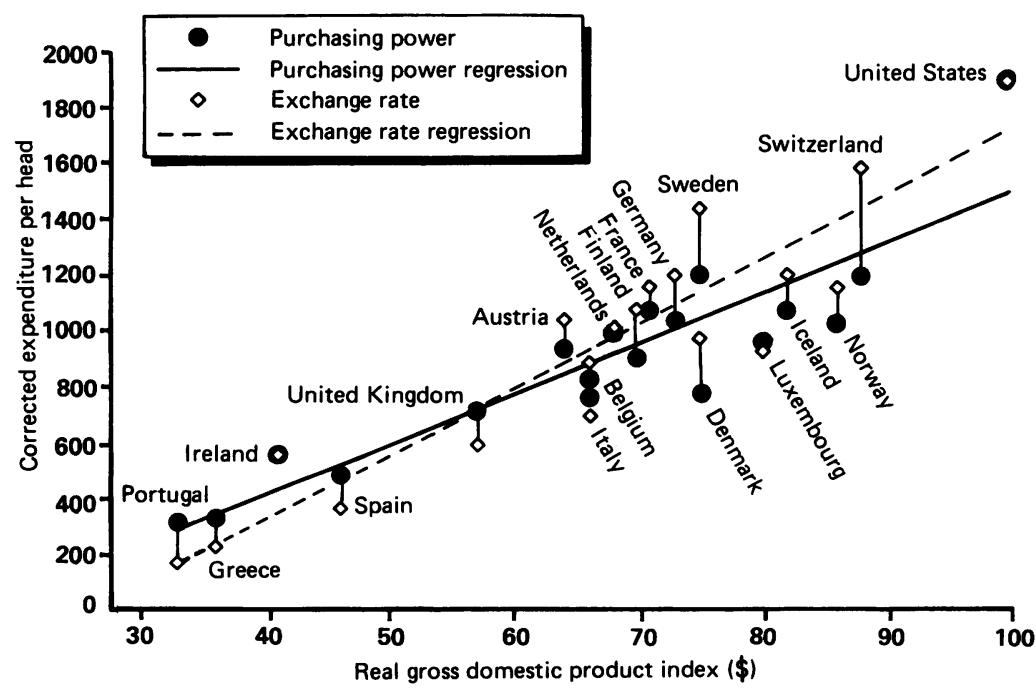

Total health care expenditure per head compared with gross domestic product for selected countries, $1986 .{ }^{3}$ Expenditure is expressed in \$ converted by exchange rates and purchasing power parties. ciably less than the country can afford and that the extra money can be raised either by taxation or by diverting money from some other area of public expenditure.

In the United Kingdom only half the amount/ head of population is spent on health care compared with some other countries (figure). ${ }^{3}$ Obviously the amount spent is related to the gross domestic product of the country, and the problem is mainly that of the relatively poor performance of the British economy, but that is not the whole story. The figure shows the amount spent on health care related to the gross domestic product of the country concerned. This relationship is shown with the currency conversions to $\$$ made by money market rates. Conversions can also be made by relating different currencies according to what a unit of currency actually buys in goods and services in that country using purchasing power parities. Although such international comparisons are fraught with problems it seems that poorer countries buy more health care with less money, presumably because health care workers are paid less well. ${ }^{4}$ Thus it is likely that some part of an increase in the proportion of gross domestic product spent on health care in a weaker economy will go towards increasing salaries rather than towards buying more health care; expenditure on health care in Canada is about $40 \%$ higher than in the United Kingdom, but the resources available for health care measured by purchasing power parities is about the same. ${ }^{5}$ It is also useful to note that public satisfaction with the health care system in Canada (which has some features of the new NHS) exceeds that in the United Kingdom. ${ }^{6}$ In addition, a larger proportion of the total funding of health care in the United Kingdom is provided from public expenditure than in most other comparat:e countries and even in Sweden more is spent on private care than in this country.

While we may argue that the government should give more money to the NHS, it is unrealistic to believe that our problems would then be solved. Over the last decade the demand for resources has totally overwhelmed the country's ability to pay. In spite of more doctors (how many paediatricians were there in your hospital in 1970 compared with now?), nurses and equipment, the introduction of intensive care for neonates and children, new treatments for cancer and previously fatal diseases such as renal failure, and many other factors affecting all age groups-not least the increased expecta- 
tion of life-no country can meet all the demands of the whole population. ${ }^{2}$ In the United Kingdom, for example, the increased provision for community services has led to the funding of the acute hospital sector being relatively restricted.

\section{Clinical efficiency and effectiveness}

The NHS is already rationed in the sense that not everyone can receive the treatment they want or occasionally need when they require it. The increasing dissatisfaction expressed by professionals in the service, by commentators and by patients, ${ }^{6}$ led to the government's review and subsequent changes in the NHS Act. ${ }^{2}$ Though there has been much criticism of the changes few credible alternatives have been presented. The underlying principle of the changes is to ensure that the money spent is used as efficiently and effectively as possible and, importantly, that equity is preserved.

We need to understand much more clearly what medical interventions are effective and what they cost so that their values can be assessed. The concept of value relates to the components of quality, quantity, and cost. Quality embraces both consumer satisfaction and medical outcome. In a service with limited cash quantity is also an issue of quality, because a high cost service with limited access may deny treatment to some who would benefit if a cheaper service was provided. One approach is to define acceptable standards of quality and then strive for maximum efficiency to increase quantity.

Many judgments about quality are necessarily subjective. None the less we have only to consider how many children have died or been severely damaged over many years by unnecessary tonsillectomies to realise that we do not have to look to the last century for examples of unnecessary and harmful medical interventions.

There is a need for much more rigorous examination of outcome of treatment in all disciplines, with more clinical trials and follow up studies. ${ }^{7}$ The recent studies comparing streptokinase and higher cost alternatives for treating myocardial infarction are exemplary. ${ }^{8}$ We need to recognise that low volume services are often of poor quality. ${ }^{9}$ It is these concepts that underly medical audit and resource management, which are themselves key points in the new arrangements. They also underly the recent appointment of a director for research and development in the NHS to introduce new projects in this area.

Resource management (or clinical efficiency) and medical audit (clinical effectiveness) must be linked. To have a drive for efficiency without regard to effectiveness would be dangerous whereas the reverse is unrealistic in a service limited by cash.

The other key change in the NHS is that which separates the commissioners or buyers of health care from the providers and this is also directed at clinical efficiency and effectiveness. The concept is that informed professionalseither primary care doctors or the new health authorities-will decide on behalf of and with the patient what treatment should be purchased and from whom. It seems to me to be inevitable that this will lead to some treatments of doubtful value not being available on the NHS.

Those of us who work in secondary care, particularly in hospitals, will have to show that what we do is effective and efficient and ensure that our service delivers care of the quality and quantity that has been promised.

\section{Organisation of hospital services}

The changes outlined above will require serious alterations in the way we work and certain safeguards if the principles of medical practice are to be protected and if the vocational element in our contribution is to be satisfied. This latter point is often discounted but young people enter the NHS to serve, and most of the older doctors, nurses, and administrators have not lost sight of this vision; it sustains the service.

A fundamental change that is required is the management of hospitals by care groups or clinical teams rather than along the traditional functional lines. The tradition has been for each professional group to manage itself and for various groups (usually committees) to be used in an attempt to coordinate the activities of doctors, nurses, clerical staff, administrators, and so on. A little thought will enable the nonsense of such arrangements to be perceived. What matters is the service that is being delivered to particular groups of patients and all who contribute to this service need to manage themselves as a group. This implies that doctors, nurses, and others will work together, sharing responsibilities and even sharing tasks.

George Bernard Shaw remarked that all professions are a conspiracy against the laity, and sometimes the effect of specialisation between or within professions is to deny the competence of anyone else to carry out a particular function. As a paediatric nephrologist I need to recognise that not all children with kidney problems require my attention; indeed, to suggest otherwise would be inefficient to both the patient and the service-and even dangerous given the need to consider the whole child and family.

The care group should control its own costs and audit its activities in terms of clinical efficiency and effectiveness. It will require timely, accurate budgeting systems and will need to liaise with other groups and with the central hospital management and services. It is important to ensure decentralisation of responsibility and authority to the managers of the care group in equal measure. This is sometimes resisted, but to have responsibility without authority is demoralising whereas authority without responsibility is dangerous. Those who deny such arrangements should consider how else contracts can be negotiated and delivered.

\section{The role of the doctor}

The consultant together with other senior staff from other professions will have a key managerial role in such a care group. We believe that professional accountability to patients within each profession can be maintained by separating 
it from managerial accountability, which is concerned with the proper use of resources. ${ }^{10}$

If a doctor is to take a managerial role in a clinical group and maintain clinical competence (which is an important facet of leadership), however, then he or she will require assistance within a multidisciplinary team. In our hospital the paediatric director is assisted by a business manager and a nurse manager, and each of the five specialised clinical teams that comprise the directorate has its own budget with decentralised facilities and management arrangements.

The paediatric service

Paediatricians should urgently consider what comprises the child health service in their district, and argue persistently for proper management arrangements for it based on the principles outlined above.

The Court report recommended implementation of a dual system of provision of child care between primary and secondary care, with the community and hospital childrens services joining to provide a comprehensive service. ${ }^{11}$ Under this scheme some professionals at present in the community services (such as health visitors) may be called upon to work with the primary services and family practices; others will join the secondary service.

The role of clinical medical officers must be defined and understood. They have many responsibilities which include: review of all handicapped children in mainstream education, the provision of selective advice to the school health service, the provision of service for children with special educational needs, initial assessment of suspected child abuse, the maintenance of the 'special needs' register, the evaluation of cases for court proceedings, and the clinical review of children in statutory and voluntary day nurseries.

These duties are in addition to routine child health surveillance and immunisations. As general practitioners and health visitors take more responsibility for routine tasks including screening we should be able to move towards reducing the number of clinical medical officers, while providing a more specialised and efficient service. This will happen only if the service is led by consultants and incorporates adequate training and career prospects that are comparable with those in other specialties within paediatrics.

The NHS has always insisted that it is a consultant led service and properly appointed consultants and principals in general practice are responsible for the training and actions of junior doctors. This principle should be maintained, with clinical medical officers being responsible to the district consultant community paediatricians.

Paediatrics is primarily concerned with development and the need to ensure that the impact of disease or disability on a child is minimised as far as possible, thus allowing the maximum potential to be achieved. Such a concept can only be embraced by integration of community and acute hospital services for children. Integration of health services for children is government policy (Secretary of State for Health. Letter to President of British Paediatric Association, 3 August 1989), but although government can play a permissive role it is a local decision to work out how best this can be achieved.

There is bound to be uncertainty as the new arrangements for separation between commissioning authorities and providers come into effect. For children's services it is logical for the acute hospital services and the community paediatric services to combine in a single care group. District general hospitals could be managed in conjunction with their 'outreach' services in child health, and probably in midwifery, mental illness and geriatrics.

'Outreach' services are those that provide continuing care in the community for those who have been treated in hospital. In addition to this, however-and more importantly-there are the community based services. It is appropriate for the base of these services to remain outside the hospital. This does not mean that they cannot be managed in the same unit as hospital services, with 'outreach' services and community based services combining into one single care group. Such a plan has been developed by Professor David Hull. ${ }^{12}$ In addition, the British Paediatric Association has produced a policy document on the role of the consultant paediatrician (community child health). ${ }^{13}$ This describes an integrated child health service and the role and training of clinical medical officers, senior clinical medical officers, and consultant paediatricians (community child health).

Integration of community and hospital services would in my opinion be facilitated by a common management structure and a common budget, but where this is not agreed then an integrated child health service needs to be ensured by other means.

The interface between primary and secondary services must also be organised. Many districts have divided their localities into 'patches' with a patch manager who is responsible for coordinating services. Under the new arrangements the patch manager could be responsible for both the provision of some services and the subcontracting of others from separate providers. The child health community service could then be subcontracted from the integrated hospital and community paediatric service. In addition the patch manager would serve as the liaison officer between the various providers including the relevant primary care services. Non-medical staff such as speech therapists, occupational therapists, physiotherapists, and health visitors are vital components of the child health service. Some will find it more appropriate to relate to primary care services based on general practice whereas others will be part of the integrated child health service.

If full integration of all staff who work in child health both in hospital and in the community into a common management structure is not agreed, then consideration should be given to all medical staff being managed within one unit so that appropriate training and flexible delivery of service is facilitated. Again the patch manager in the community could subcontract 
from the integrated child health medical service. A third possibility would be for consultant community paediatricians to have dual contracts with the acute hospital and community units, but this would seem to be less satisfactory. In any case it must be agreed that the clinical medical officers and the senior clinical medical officers are accountable both professionally and managerially to the consultant paediatricians (community health).

\section{Conclusion}

Changes in the structure of the NHS were inevitable given the problems that were created by the growing discrepancy between supply and demand. Whether or not the changes are welcomed we must understand them and the reasons why they have been introduced. Above all, paediatricians need to grasp the opportunity to improve the management of child health services and have a leading role in trying to ensure their success.

I thank Mr Gwyn Bevan, Professor Roger Dyson, and Dr Margaret Lynch for their help in the preparation of this paper, though the opinions expressed are personal.
1 Appleyard WJ. Childrens services in the new NHS-a struggle for survival? Arch Dis Child 1990;65:635-7.

2 Ham C, Robinson R, Benzeval M. Health check; health care reforms in an international context. London: King's Fund reforms in an internationa
Institute, 1990:1-112.

3 Organisation for Economic Cooperation and Development Health care systems in transition, the search for efficiency. Paris: OECD, 1990.

4 Parkin DW. Comparing health service efficiency across countries. Oxford Review of Economic Policy 1989;5:75-88.

5 Parkin DW, McGuire AJ, Yule BF. What do international comparison of health care expenditure really show? Comcomparison of health care ex

6 Blendon RJ. Three systems; a comparative survey. Health Management 1989;first quarter:2-10.

7 Hopkins A. Measuring the quality of medical care. London: Royal College of Physicians of London, 1990:1-90.

8 International Study Group. In hospital mortality and clinical course of 20891 patients with suspected acute myocardial infarction randomised between altepase and streptokinase with or without heparin. Lancet 1990;336:71-5.

9 Black N, Johnston A. Volume and outcome in hospital care: Evidence, explanations and implications. Health Services Management Research 1990;3:108-14.

10 Chantler C. How to be a manager. BMF 1989;298:1505-8.

11 Report of the Committee on Child Health Services. Fit for the future. London: HMSO, 1976. (Cmnd 6680.) (Court report.)

12 Hull D. Health services for children. Nottingham: Nottingham Department of Child Health, University of Nottingham 1990 .

13 British Paediatric Association. Consultant paediatrician (community child health). London: British Paediatric Association, 1990. 